\title{
Introduction to the special issue information technology in Korea: its role in firm success and economic development
}

\author{
Young U. Ryu $\cdot$ Jae Kyeong Kim
}

Published online: 22 February 2013

(c) Springer Science+Business Media New York 2013

Korea is one of a few countries that have achieved significant economic growth in the recent two decades. The early agricultural economy in 1940s and 1950s had gradually changed due to the government-driven economic development plans started in 1960s. The early emphasis was made on both modernization of the agricultural industry and the promotion of the heavy and chemical industry. After seeing the success in the heavy and chemical industry, the government and the private sector worked together toward more advancement in the heavy and chemical industry in 1970s. However, the government and some private firms realized the long-term potential in the electronics and telecommunications industry and started establishing infrastructure for electronics and telecommunications industry in 1980s. The blossoming of the information technology (IT) sector including the electronics and telecommunications industry and other related areas was observed in the late 1990s and beyond.

The past two decades' growth in the IT sector has substantially enhanced the Korea's national economy as well as the firm-level efficiency. In this special issue that consists of five papers, we would like to see evidences supporting IT's contribution to firm success and the economic development in Korea.

The first paper, "The role of IT in Korea's Economic Development," reports various economic indices that show

\footnotetext{
Y. U. Ryu ( $\square)$

School of Management, University of Texas at Dallas,

Richardson, TX, USA

e-mail: ryoung@utdallas.edu

Y. U. Ryu · J. K. Kim

School of Management and Management Research Institute,

Kyung Hee University, Seoul, Korea

e-mail: jaek@khu.ac.kr
}

direct and indirect roles or positions of IT in Korea. It also reports the government's efforts to promote the development of information and communications technologies.

The second paper, "Effects of Strategic Alignment on IS Success: The Mediation Role of IS Investment in Korea," empirically validates the role of IT investment in the improvement of business value in Korea. The study uses business executives' views and perceptions in the empirical analysis. The third paper, "The Role of R\&D and Corporate Governance in Korea: IT Firms versus Non-IT Firms," compares different roles and effects of R and D investment between IT firms and non-IT firms in Korea. The study discovers that higher $\mathrm{R}$ and $\mathrm{D}$ investment results in higher firm valuation for IT firms. This leads to an indirect evidence of IT's contribution at a firm level.

The fourth paper, "Factors Affecting the Perceived Usability of the Mobile Web Portal Services: Comparing Simplicity with Consistency," addresses the status of mobile data service in Korea. In particular, it reports Korean users' usability perception of mobile Web services. Finally, the fifth paper, "Data Quality and Firm Performance: Empirical Evidence from the Korean Financial Industry," addresses the role of IT delivering high quality data in the Korea's financial sector. It provides a firm-level empirical evidence showing the effect of data quality on firm performance.

All these papers directly or indirectly show the importance of IT in Korea's economic development. Though part of IT's contribution may be due to economic, cultural, and political aspects specific to Korea, the fact that IT serves as a vehicle to bring economic success in Korea should be a valuable lesson to many developing countries. 